\title{
Dynamic Torsion Testing of Nanocrystalline Coatings Using High-Speed Photography and Digital Image Correlation
}

\author{
by F. Barthelat, Z. Wu, B.C. Prorok, and H.D. Espinosa
}

\begin{abstract}
The strength and ductility of microcrystalline and nanocrystalline tungstsen carbide-cobalt (WC-Co) cermets have been evaluated by employing a stored energy Kolsky bar apparatus, high-speed photography and digital image correlation. The test specimens were thin-walled tubular Al7075-T6 substrates $250 \mu \mathrm{m}$ thick, coated with a $300 \mu \mathrm{m}$ thick microcrystalline or nanocrystalline WC-Co layer with an average grain size of about $3 \mu \mathrm{m}$ and $100 \mathrm{~nm}$, respectively. Dynamic torsion experiments reported in this paper reveal a shear modulus of $50 \mathrm{GPa}$ and a shear strength of about $50 \mathrm{MPa}$ for both microcrystalline and nanocrystalline WC-Co coatings.

The use of high-speed photography along with digital image correlation has shown that damage to the coating coincides with a significant softening on the stress-strain curve. The coating failed in mode III, and strong interactions between the crack faces were probably responsible for the increase in load after failure of the coating. The overall failure of the coating-substrate system was not brittle but rather progressive and controlled by the ductility of the aluminum substrate.

A methodology for investigating damage kinetics and failure has been established. This methodology can be applied to examine the behavior of other advanced materials that can be manufactured as coatings on ductile substrates. Manufacturing coatings free of initial microcracks remains a significant challenge. Research on optimization of the spray deposition parameters should be pursued to produce high-quality nanostructured coatings that can fully exploit the benefits of nanosize grains.
\end{abstract}

KEY WORDS-Nanostructured materials, WC-Co, dynamic properties, wave propagation, stress-strain relationship measurements

\section{Introduction}

Tungstsen carbide-cobalt (WC-Co) cermets are employed primarily in applications where high wear resistant is needed. Properties of high hardness and toughness have encouraged their widespread use in a variety of applications, including mining, grinding, and metal cutting. Conventional grades of these cermets possess grain sizes in the $1-10 \mu \mathrm{m}$

F. Barthelat (SEM Member) is a PhD Candidate, Z. Wu is a Post-Doctoral Student, B.C. Prorok (SEM Member) is an Assistant Professor, and H.D. Espinosa (espinosa@northwestern.edu) (SEM Member) is a Professor, Department of Mechanical Engineering, Northwestern University, 2145 Sheridan Road, Evanston, IL 60208-3111.

Original manuscript submitted: February 21, 2003.

Final manuscript received: February 21, 2003. range, with a morphology composed of a hexagonal WC phase bound together with a Co phase. Mechanical properties are significantly influenced by this microstructure in that hardness increases with grain size in accordance with the Hall-Petch relation. ${ }^{1,2}$

Recent work has indeed demonstrated that nanostructured cermets offer improved mechanical properties over their coarse-grained counterparts. ${ }^{3}$ Nanostructured materials are of great interest in systems where nanograined morphology may improve the ductility of what would otherwise be brittle materials. As a result, they possess high interface-to-volume ratios that can expand plasticity and strain to failure of normally brittle materials. ${ }^{4,5}$ Nanostructured materials can also exhibit increased hardness that follows the Hall-Petch relation to a critical point prior to saturation. ${ }^{6,7}$ These benefits stem from the large number of nanosized grains per unit volume and changes in deformation mechanisms from plasticity inside grains to grain boundary shearing. ${ }^{5,8}$ They are also subject to the actual microstructure and nanostructure of the material. For instance, the presence of porosity in a nanostructured material results in a lower than expected hardness and affects various other mechanical properties as well..$^{9,10}$

For the WC-Co cermet material, properties of increased hardness and enhanced strain to failure are very desirable. These advantages have been well documented for other submicrometer grain sized ceramics. ${ }^{11-13}$ Some studies have reported superplastic behavior at elevated temperature with strain to failure above $100 \% .{ }^{13}$ Nanocrystalline ceramics have even smaller grain sizes, and may exhibit larger strains. ${ }^{14}$

The wear resistant applications of WC-Co cermets very often expose them to mechanical conditions involving local dynamic loading and high strain rates. Testing of materials under such loading conditions presents special challenges. ${ }^{15}$ Dynamic fracture toughness can be evaluated by a number of techniques that include the Charpy test, ${ }^{16,17}$ the drop-hammer experiment, ${ }^{18}$ and the plate-impact experiment. ${ }^{19}$ In employing these methods, the energy applied to the specimens is considerable, resulting in unstable growth upon crack initiation. Similarly, damage and inelasticity can be addressed using dynamic testing with specimen recovery. ${ }^{20-22} \mathrm{~A}$ further consequence of these methods stems from computational and theoretical considerations that make up the basis for identifying damage initiation and evolution. ${ }^{23,24}$

It is essential for present and future application of nanostructured coatings to be able to predict their failure kinetics and high strain rate response. With this in mind, a simple 
and accurate technique for studying dynamic loading conditions is the modified split Hopkinson pressure bar. ${ }^{25}$ This method has the advantage of loading the material under nearly uniform stress and strain rate. The integration of high-speed photography and digital image correlation (DIC) allows for the monitoring of specimen state during testing. By this approach, a correlation can then be made between failure initiation and the stress-strain state of the specimen.

In this paper, we investigate the response of microcrystalline and nanocrystalline WC-Co coatings subjected to high strain rate loading conditions and we examine the effect of loading rate on the failure mode. We also evaluate the strength and ductility of the nano-grain-sized coatings with unique instrumentation and specimen configuration.

\section{Experimental Procedure}

\section{Materials and Processing}

Microcrystalline and nanocrystalline WC-Co coatings were produced by a high velocity oxygen fuel (HVOF) proprietary spraying process developed by A\&A Co., Inc., South Plainfield, NJ. In this study, the alloy Al7075-T6 was machined as a thin-walled tube and used as a substrate. Both coated and uncoated aluminum specimens were tested.

The geometrical dimensions of the $\mathrm{WC}-\mathrm{Co}$ nanocoated samples used in the dynamic torsion test are given in Fig. 1. Figure 2 shows photomicrographs of microsized (3-4 $\mu \mathrm{m}$ ) and nanosized $(100 \mathrm{~nm})$ grain structures. Both materials had $12 \%$ cobalt content.

The ends of the sample were fixed to the incident and transmission bars by means of a high strength and fast curing adhesive (DEVCON 5 minute epoxy).

\section{Mechanical Testing}

Our modified stored-energy Kolsky bar was used to obtain shear stress-shear strain curves at high strain rates. 22,26,27 The bar was integrated with a high-speed photography rig to observe deformation events and correlate them to specific points along the stress-strain curve.

Microindentation and nanoindentation tests were performed on materials of both grain structures. The microindentation tests were carried out with a Buehler Micromet II indenter. Nanoindentation was performed with an MTS XP nanoindenter/atomic force microscopy (AFM) combination in a single platform.

\section{High-Speed Photography}

High-speed photography was used to monitor specimen inelasticity during testing. A Cordin Model 220-8 digital camera and K2 Infinity long distance microscope were used with a SUNPAK Auto 120J TTK high-power flash to acquire the images. Frames were captured at fixed intervals with exposure times of $1 \mu \mathrm{s}$. The incident pulse, at gage station $1,{ }^{22}$ was used to trigger the camera and flash. Full displacement fields were calculated from the sequence of images, and were used to monitor damage or shear localization in the specimen with respect to the stress-strain response.

\section{Digital Image Correlation}

The principle of the digital correlation technique is to correlate an "undeformed" and a "deformed" digitized image of the specimen surface. ${ }^{28,29}$ Random dark and light features created (using, for example, toner powder) or naturally present on the surface of the specimen (shades due to roughness) translate into a distribution of intensity (pixels) in the digitized image. The local distributions of pixel intensity are typically used to correlate the images. The correlation procedure uses a reference picture of the speckle, and a "deformed" picture where the surface has been distorted by deformations. The following numerical scheme is used. ${ }^{28,29}$ Consider a square subset in the undeformed, reference image, and a point $\mathrm{P}$, of coordinates $(x, y)$, located inside this subset. After deformation, the subset may have moved to a new location and $\mathrm{P}$ moved to $\mathrm{P}^{*}$, of coordinates $\left(x^{*}, y^{*}\right)$, namely

$$
\begin{aligned}
& x^{*}=x+u+\frac{\partial u}{\partial x} \Delta x+\frac{\partial u}{\partial y} \Delta y \\
& y^{*}=y+v+\frac{\partial v}{\partial x} \Delta x+\frac{\partial v}{\partial y} \Delta y
\end{aligned}
$$

where $u$ and $v$ are the horizontal and vertical components of the displacement of the center of the subset, and $x$ and $y$ are local coordinates within the subset. Using the dark and light features of the subset, in other words the gray-level values $F(x, y)$ in the undeformed subset and $G\left(x^{*}, y^{*}\right)$ in the deformed subset, the goal is to find the values of $u, v$ (subset displacement) and $\partial u / \partial x, \partial u / \partial y, \partial v / \partial x, \partial v / \partial y$ (subset distortion) that satisfy the best match between undeformed and deformed subsets. A way to achieve this is by minimizing the correlation function $S$ given by

$$
\begin{aligned}
& S\left(u, v, \frac{\partial u}{\partial x}, \frac{\partial u}{\partial y}, \frac{\partial \nu}{\partial x}, \frac{\partial \nu}{\partial y}\right) \\
& =1-\frac{\sum[F(x, y) \cdot G(x *, y *)]}{\left[\sum F(x, y)^{2} \cdot \sum G(x *, y *)^{2}\right]^{1 / 2}} .
\end{aligned}
$$

A Newton-Raphson scheme is used to optimize $S$. Because of the discrete nature of the digital image, the resolution is limited by the size of the pixel. In order to increase this resolution, the gray values of the subset are fitted with a function, typically a spline surface. Gray values between pixels can therefore be interpolated, and the search is performed using this function. This procedure allows the determination of subpixel displacements between two images. Once the displacements and deformations of the first subset are found, another subset is taken in the undeformed image and the same procedure is repeated. This allows the determination of the full field displacement between the undeformed and deformed images. The correlations were performed using the software VIC 2D (Video Image Correlation Package for a two-dimensional problem. (C) Correlated Solutions, 1998).

\section{Wave Propagation Formulae}

In the dynamic shear tests, the strain rate can be expressed as a function of incident, reflected, and transmitted shear strains, namely

$$
\dot{\gamma}_{s}=\frac{r_{s} c}{r_{b} L_{s}}\left\{\gamma_{T}(t)-\left[\gamma_{I}(t)-\gamma_{R}(t)\right]\right\}
$$

where $\gamma_{I}, \gamma_{R}$, and $\gamma_{T}$ are the incident, reflected and transmitted shear strains, respectively, $r_{s}$ is the centerline radius 


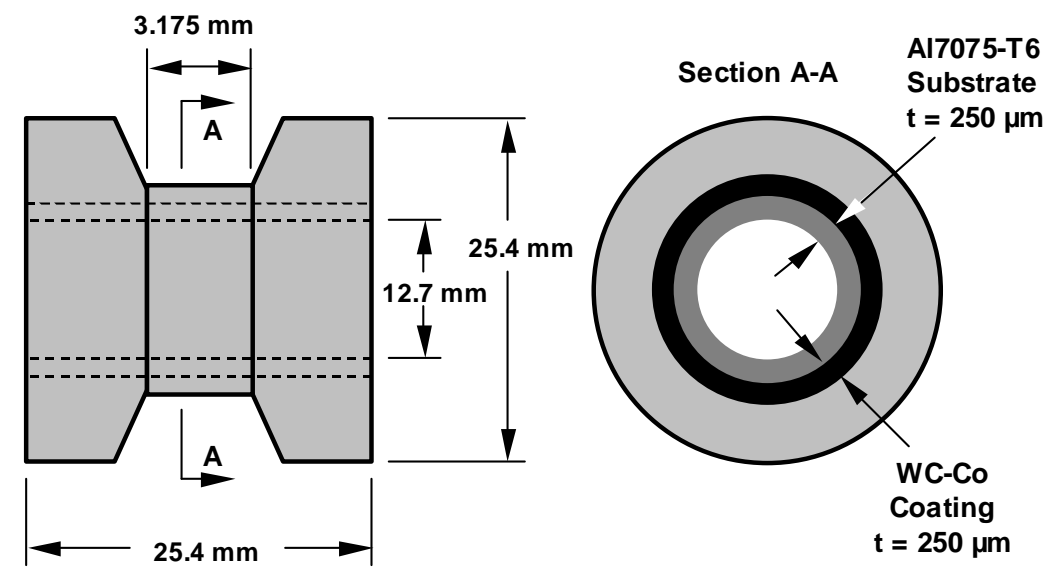

Fig. 1-Schematic diagram of the WC-Co coated dynamic torsion specimen. The dimensions of the Al7075-T6 substrate are identical for uncoated specimens.
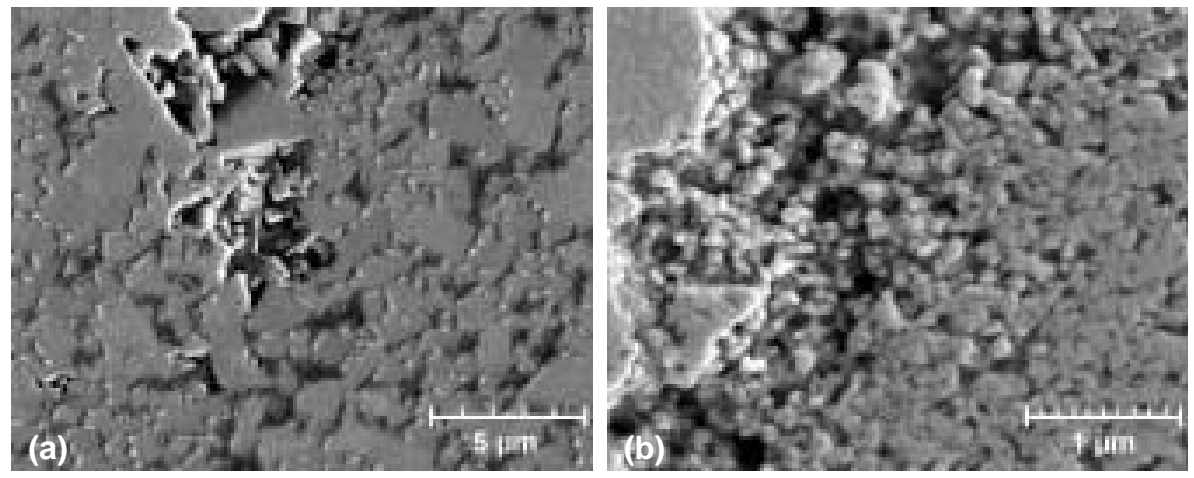

Fig. 2-Photomicrograph of WC-Co (a) micro- and (b) nano-grain-sized coatings

of the thin-walled sample, $L_{s}$ is the length of the sample, $r_{b}$ is the radius of Kolsky bar, and $c=\sqrt{G_{b} / \rho_{b}}$, the torsional wave propagation speed in the bar.

Assuming a homogeneous state of strain in the specimen, the transmitted pulse is the difference between the incident and reflected pulses $\left(\gamma_{T}(t)=\gamma_{I}(t)+\gamma_{R}(t)\right)$. Hence, eq (3) can be rewritten as

$$
\dot{\gamma}_{s}=\frac{2 r_{s} c}{r_{b} L_{s}} \gamma_{R}(t) .
$$

The reflected strain $\gamma_{R}$ can be determined from the reflected torque, namely, $\gamma_{R}=T_{R} / G_{b} \pi r_{b}^{3}$, where $T_{R}$ is the measured reflected torque from the reflected pulse signal, and $G_{b}$ is the shear modulus of the bar. The sample shear strain, $\gamma_{s}$, can be easily determined by integrating eq (4). This method is later on referred to as integration.

In the case of a single material specimen, the average shear stress in the sample is computed directly from the transmitted pulse, $T_{T}$, namely, $\tau_{s}=T_{T}\left(I_{p, s} / r_{s}\right)=T_{T} / 2 \pi r_{s}^{2} t_{s}$, where $I_{p, s}$ is the sample polar moment of inertia and $t_{s}$ is the cylindrical shell thickness of the thin-walled sample.

For double-layered specimens, such as the WC-Co nanocoating on an aluminum thin-walled substrate (see Fig. 1), the contribution of the aluminum substrate needs to be subtracted from the overall torque. Dynamic testing of a thin-walled $\mathrm{Al}$ 7075-T6 specimen without coating provides the torque-strain response for the substrate only. Assuming that shear strains in coating and substrate are identical and that the substrate with coating and the substrate alone undergo the same loading conditions (same strain rate), the substrate contribution can be subtracted from the overall response.

It is important to note that compatibility in the doublelayered specimens and/or homogeneous deformation are violated when debonding at the aluminum-WC/Co interface or shear localization occurs. Additional details concerning this data reduction procedure can be found in Barthelat et al. ${ }^{30}$ and Espinosa. ${ }^{31}$

\section{Results and Discussions}

\section{Microindentation and Nanoindentation}

To gain insight into the tested materials, the hardness of the micro- and nano-grain-sized WC-Co was evaluated. The results are summarized in Table 1 . It should be noted that the load and depth shown in this table cannot be directly correlated between the microindentation and nanoindentation experiments due to differences in diamond tip geometries. They are given only as a relative comparison to evaluate tip depth into the coating. 


\begin{tabular}{ccccc}
\hline & Load $(\mathrm{kg})$ & Depth $(\mathrm{nm})$ & $\begin{array}{c}\text { Hardness } \\
\text { Micro-grain-sized } \\
H_{V}(\mathrm{GPa})\end{array}$ & $\begin{array}{c}\text { Hardness } \\
\text { Nano-grain-sized } \\
H_{V}(\mathrm{GPa})\end{array}$ \\
\hline Microindentation & 1.000 & 7892 & 11.9 & - \\
& 0.500 & 5557 & 12.0 & - \\
& 0.300 & 4169 & 12.8 & 12.3 \\
Nanoindentation & 0.200 & 3416 & 12.7 & 12.5 \\
& 0.100 & 2387 & 13.0 & 13.6 \\
& 0.009 & 500.0 & 20.4 & 19.3
\end{tabular}

Microindentation tests at loads from 0.1 to $1 \mathrm{~kg}$ revealed that hardness remained relatively uniform for both grainsized structures yielding values between 12-13 GPa. Indentation tests at loads greater than $0.3 \mathrm{~kg}$ were not possible for the nanosized material due to surface roughness and porosity of the specimen. Figure 2 shows the polished cross-section of a nanocrystalline WC/Co torsion specimen, illustrating the degree of coating porosity.

Nanoindentation tests at depths of 200 and $500 \mathrm{~nm}$ revealed a significant change in deformation behavior. The microsized material exhibited an increase in hardness to $\cong 20 \mathrm{GPa}$ while the nanosized material exhibited a hardness equivalent to the microindentation data, at a depth of $500 \mathrm{~nm}$, and then increased to $\cong 20 \mathrm{GPa}$ at a depth of $200 \mathrm{~nm}$.

Figure 3 shows AFM images of nanoindents made at a depth of $200 \mathrm{~nm}$ for both grain sizes. Note the asymmetric pile-up of material for the micro-grain-sized material, likely a result of indenting a single-crystal WC grain. In contrast, the pile-up of the nano-grain-sized material is more uniformly distributed around the periphery. In this specimen, etching revealed that several of the nanosized grains were in contact with the indenter tip.

The hardness data of the micro-grain-sized material can be summarized as follows. In the regime of microindentation, the material behavior was governed by the $\mathrm{WC}-$ Co composite microstructure with a large number of grains participating and controlling the deformation process. Nanoindentation data revealed an increase in hardness, likely a result of indenting single-crystal WC grains.

For the case of the nano-grain-sized material, at low indentation depth (below $200 \mathrm{~nm}$ ), the indentation data did show the expected increase in hardness usually observed in a nanostructured material. When the indentation depth was such that the volume of interrogated material contained pores, the nanocrystalline coating performed in a manner similar to the micro-grain-sized material. No increase in relative hardness was observed until nanoindentation was limited to a depth of $200 \mathrm{~nm}$. The effect of porosity on nanostructured material strength will be further discussed in the following section.

\section{Dynamic Torsion}

\section{VALIDATION TESTS ON AluminUm SUBStRates}

Aluminum 7075-T6 substrates (without coatings) were first tested using the method outlined in the Experimental Procedure section. Because of the smooth, shiny aspect of the surface of the specimen, a random dark and light pattern was created by spraying toner powder on a thin layer of white acrylic paint applied on the surface of the gage region of the specimen. An example of displacement field given by the correlation method is shown in Fig. 5. The subset size used was $25 \times 25$ pixels, and correlations were performed every five pixels. The observed displacements are due to deformations of the specimen, but also to mechanical drift in the acquisition system (rigid body motion). Only the relative displacements (strains) are of interest in this test, and the results show an almost perfect state of shear in the specimen. From the displacements the shear strains were determined. Figure 6 shows a plot of the vertical displacement $V$ as a function of the horizontal position $x$, along different horizontal lines (the shear stress was applied along the vertical direction of the image). From this plot, the shear strain $\gamma_{x y}$ is simply given by the slope of these curves.

The shear stress in the gage was computed from the torque using a thin wall approximation (constant stress throughout the thickness of the gage), namely, $\tau_{x y}=2 T / \pi D^{2} t$, where $T$ is the applied torque, $D$ is the diameter of the specimen through the centerline, and $t$ is the wall thickness. Accurate synchronizations between load pulse and images allow correlation between torque and each high-speed pictures, as shown in Fig. 7. The resulting stress-strain curves are shown in Fig. 8. The measured properties are consistent with literature values for aluminum 7075-T6; a shear modulus of $G=$ $25 \mathrm{GPa}$ and a yield shear stress $\tau_{y}=150 \mathrm{MPa}$.

Good agreement between shear stress-shear strain curves obtained by integration and digital image correlation methods is observed. These tests provided accurate stress-strain curves for the aluminum substrate.

\section{CoAting SheAR StRESS-Strain CURVES}

Three thin-walled sample configurations were investigated. The first was an Al7075-T6 alloy thin-walled tube of thickness $250 \mu \mathrm{m}$ coated with a $250 \mu \mathrm{m}$ thick nanostructured WC-Co cermet. The second and third were uncoated Al7075-T6 thin-walled tubes of thickness 250 and $500 \mu \mathrm{m}$ respectively, used comparatively for evaluating the coatings mechanical properties.

The measured transmitted torque of the mentioned samples is plotted as a function of time in Fig. 9. For both uncoated Al7075-T6 specimens, $(\diamond)$ denotes $250 \mu \mathrm{m}$ thickness and $(\square)$ denotes $500 \mu \mathrm{m}$; the transmitted pulse has an extended steady-state region at the top of the curve with large plastic deformations being recorded. However, for the WCCo coated sample ( ), the transmitted pulse drops quickly after maximum transmitted torque is reached. This indicates that the WC-Co coating exhibits a quasi-brittle behavior and fractures at small inelastic deformations when compared to thin-walled A17075-T6 specimens. 

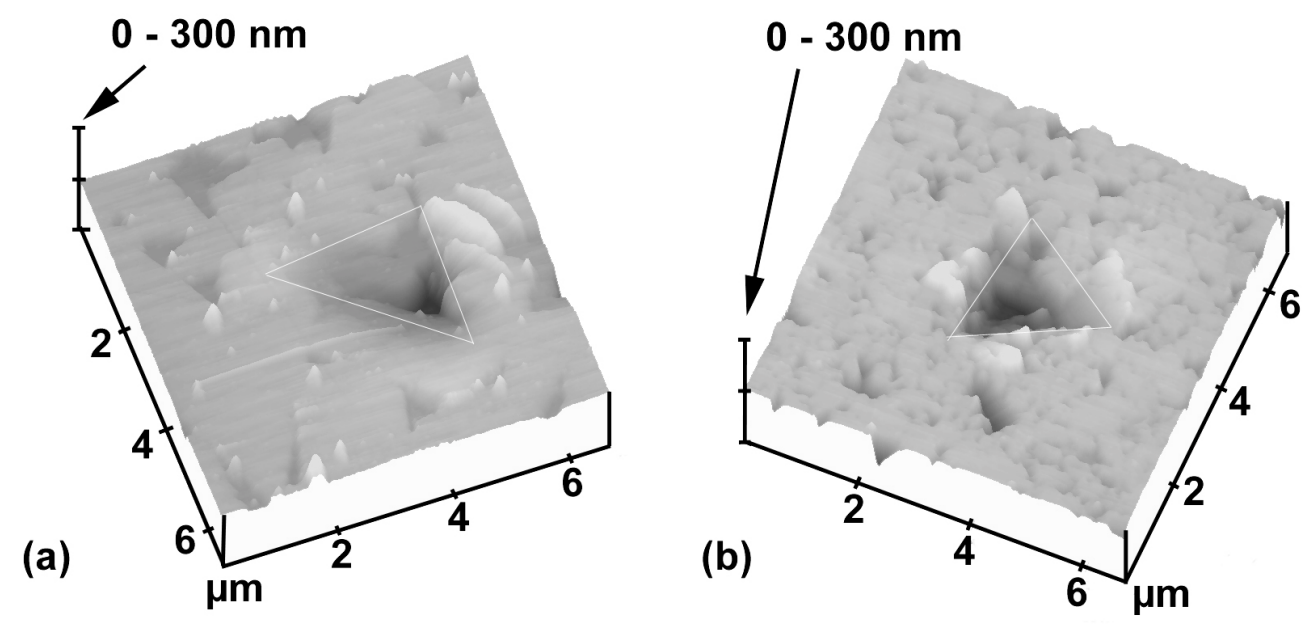

Fig. 3-AFM images of $200 \mathrm{~nm}$ deep nanoindentations in the (a) micro- and (b) nano-grain-sized coatings

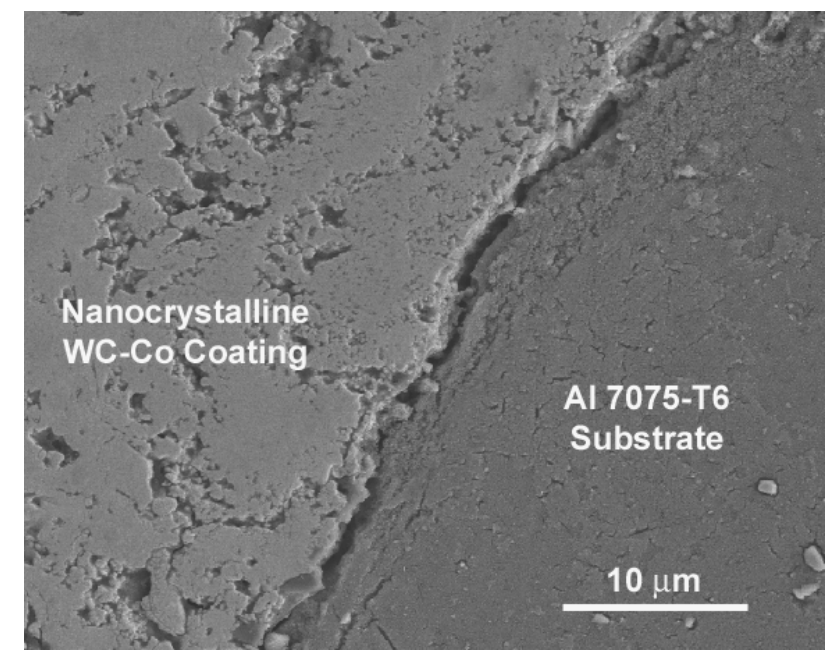

Fig. 4-SEM micrograph of a polished cross-section obtained from a nanocrystalline WC/Co torsion specimen. The micrograph illustrates the degree of porosity in the WC/Co nanocoating.
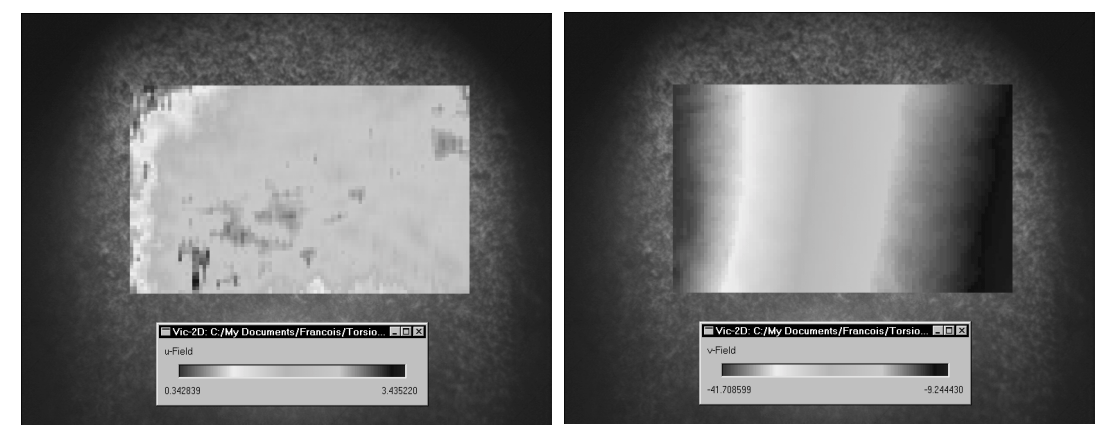

Fig. 5-Displacement profiles (left, horizontal displacement $U$; right, vertical displacement $V$ ) of the aluminum specimen surface when dynamically loaded in torsion 


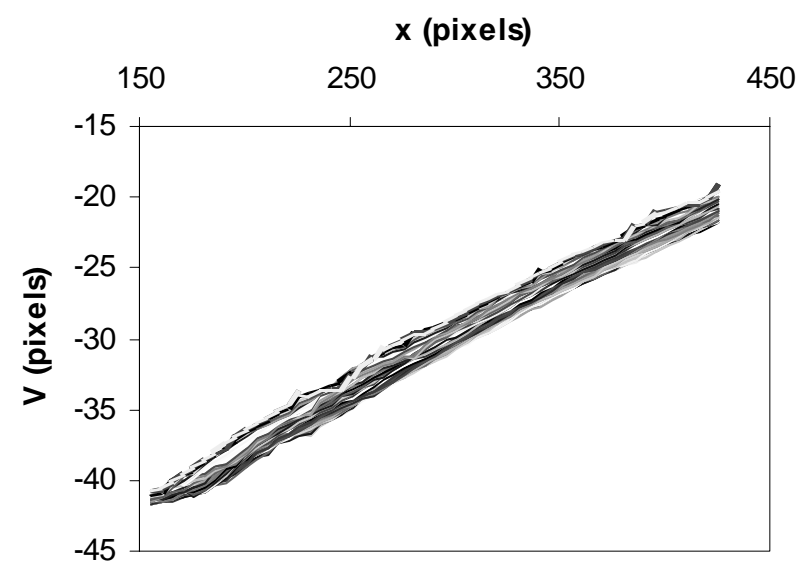

Fig. 6-Displacement $V$ along several horizontal lines

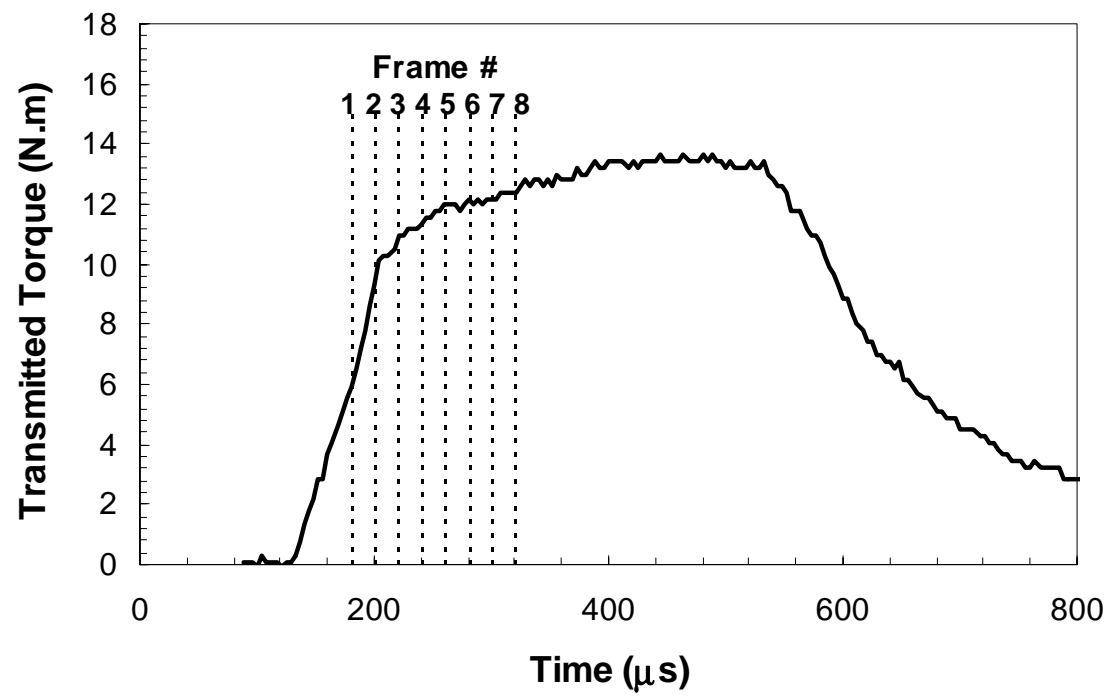

Fig. 7-Transmitted torque versus time plot obtained from dynamic torsion test performed on Al 7075-T6. Incident torque of $80 \mathrm{~N} \mathrm{~m}$. Synchronization between loading pulse and high-speed pictures is highlighted.

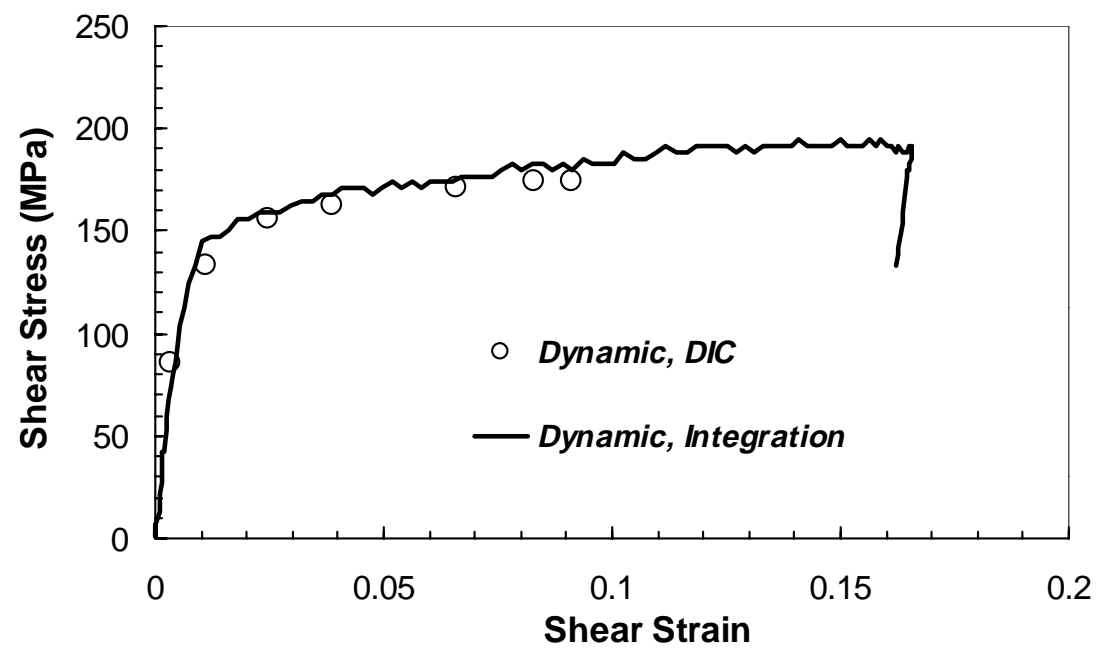

Fig. 8-Stress-strain curve from a dynamic torsion test performed on Al 7075-T6. The strain rate was $550 \mathrm{~s}^{-1}$. 


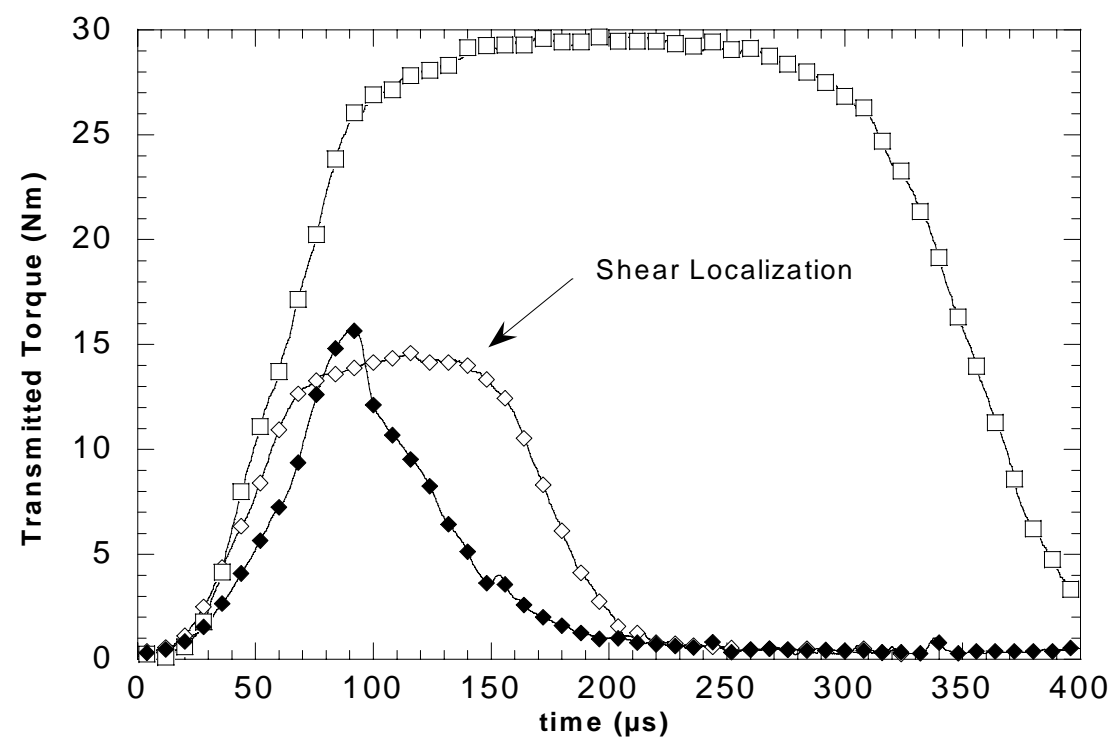

Fig. 9-Transmitted torque versus time obtained from coated and uncoated specimens: nano-grain-sized WC-Co coated Al7075-T6 thin-walled specimen with an incident torque of $190 \mathrm{~N} \mathrm{~m}(\diamond)$; uncoated Al7075-T6 thin-walled specimens of thickness $250 \mu \mathrm{m}(\diamond)$ and $500 \mu \mathrm{m}(\square)$ with incident torques of 195 and $180 \mathrm{~N} \mathrm{~m}^{-1}$, respectively.

The doubling of the wall thickness for the uncoated $\mathrm{Al}$ specimens translated into a doubling of the maximum transmitted torque. It is also observed that the transmitted pulse duration in the thinner specimen was about half the input pulse duration. The $250 \mu \mathrm{m}$ thick aluminum samples were found to be broken after the shear tests, a result of shear localization followed by fracture. This explains the reduction in transmitted pulse time to approximately one half of the pulse duration. Note that this transmitted torque history differs from the transmitted torque history reported in Fig. 7 for a similar specimen. While the plateau level of the transmitted torque is similar, the pulse duration in the experiment plotted in Fig. 7 is the full input pulse duration. This is the case because the input torque was much lower than that used in the three experiments reported in Fig. 9. As a result, shear localization and fracture did not occur.

In the analysis of the experimental results of the coated specimens, we should note that when the coating fails, the transmitted torque rapidly drops to a lower level before progressively decaying to zero. This indicates that the inner aluminum layer controls the post-failure behavior. This phenomenon is well documented under quasi-static loading by our work on nanocrystalline $\mathrm{Al}_{2} \mathrm{O}_{3} / \mathrm{TiO}_{2}$ coatings. ${ }^{30}$ Furthermore, in view that the Young's modulus of WC-Co is much greater than that of A17075-T6, the plastic deformation of the inner aluminum layer is then constrained to a much narrower region. Thus, the total plastic deformation, on the whole specimen length, is smaller than in the case of the uncoated aluminum specimen. Therefore, it can be inferred that this sudden loss of load carrying capacity of the coating prematurely triggers shear localization in the aluminum substrate.

This phenomenon was found to exist in all nanocrystalline WC-Co coated specimens subject to varying levels of incident torque. Figure 10 is a plot showing transmitted torque signatures for specimens with incident torques of $200(\bullet), 190$ $(\diamond), 180(\triangle)$, and $130 \mathrm{~N} \mathrm{~m}^{-1}(\bullet)$. It should be noted that they are plotted on an arbitrary timescale for clarity and that each data set lasted for a period of $\cong 250 \mu$ s. It is also important to note that a higher incident torque did not always correspond to a higher transmitted torque. For example, the $180 \mathrm{~N} \mathrm{~m}$ incident torque specimen exhibited the highest transmitted torque.

Typical shear stress-strain curves obtained from dynamic tests, for both micro- and nano-grain-sized coatings, are shown in Fig. 11. The initial region of both curves gives a shear modulus of about $50 \mathrm{GPa}$. At shear stresses of about $50 \mathrm{MPa}$, both curves exhibit a sudden softening (more pronounced for the micro-grain-sized coating) until the shear stress reaches $130 \mathrm{MPa}$ for the nanocrystalline coating and $100 \mathrm{MPa}$ for the microcrystalline coating. The stress response then decreases in a progressive fashion.

\section{HIGH-SPEED PHOTOGRAPHY}

Figure 12 is a series of digital images showing the surface of the nanocrystalline coating at different points on the stress-strain curve (Fig. 11). Vertical displacement fields, as found using DIC, are also shown in the insets. The displacements are inhomogeneous (probably due to initial internal damage) and no single strain could be extracted from them. However, these images were used to elucidate the mechanisms of deformation during the tests. Snapshots 1, 2 and 3 were taken within the elastic region. They clearly show inhomogeneities in the displacement field. Snapshots 4 and 5 correspond to the inelastic part of the curve. The displacement field is progressively controlled by the formation of a mode III crack (vertical in the image) revealed by the DIC technique but invisible to the naked eye. Snapshot 6 , taken as the stress started to decrease (softening part), confirms the location of the crack. Careful inspection of the image reveals a visible crack at the location predicted by the DIC.

These real-time images allow elucidation of the inelastic mechanisms in the coating-substrate system. A first phase is dominated by the elastic response of the coating-substrate 


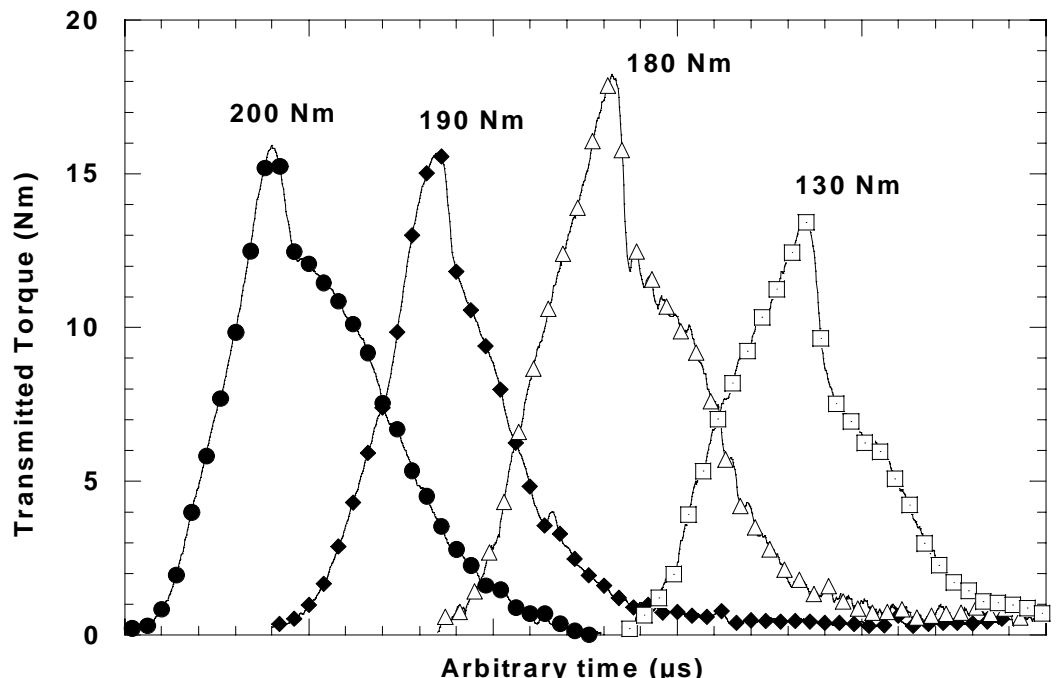

Fig. 10-Transmitted torque versus time obtained from nanocrystalline WC-Co coated specimens at varying incident torques: $200 \mathrm{~N} \mathrm{~m}(\bullet), 190 \mathrm{~N} \mathrm{~m}(\bullet), 180 \mathrm{~N} \mathrm{~m}(\triangle)$, and $130 \mathrm{~N} \mathrm{~m}(\square)$.

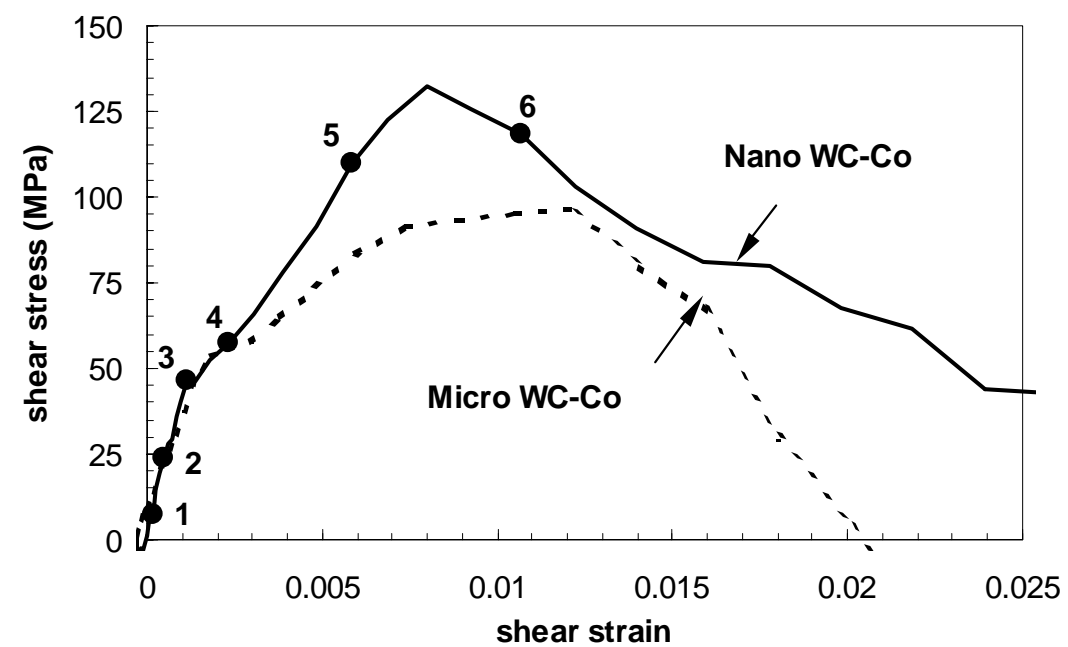

Fig. 11-Shear stress-strain curves of microcrystalline and nanocrystalline WC/Co thin-walled specimens. The input torque was kept constant and equal to $100 \mathrm{~N} \mathrm{~m}$. The strain rate was $700 \mathrm{~s}^{-1}$.

pair. Initial stochastic damage in the coating creates inhomogeneities in the displacement field. A major mode III crack then develops in the coating and a sudden softening occurs in the stress-strain curve. However, the substrate is still intact and bridges the crack faces, holding the specimen together. Frictional forces at the crack faces are likely responsible for the continuous increase of the stress response. Heavy plastic deformations of the substrate underneath the crack lead to its failure, which is ductile and translates into a progressive decrease of the stress. Total specimen failure follows.

\section{Fracture Surface Microscopy}

Figure s 13(a)-(d) show images from a coated specimen recovered after dynamic shear testing. The white box shown in Fig. 13(a) marks the region where scanning electron microscopy (SEM) was performed. SEM images at different magnifications are given in Figs. 13(b)-(d). The images show some significant amount of debonding and cracking in the coatings, as well as some porosity. The ductile behavior of aluminum is evident from the elongated features observed in the direction of shearing.

\section{Concluding Remarks}

A methodology for dynamic torsion testing of microstructured and nanostructured coating materials was developed. An energy-stored Kolsky bar apparatus together with highspeed photography and DIC was employed. The experiments consisted of loading thin-walled specimens by stress pulses well defined in magnitude and duration. The procedure was validated using an aluminum 7075-T6 substrate without coating. For the case of coated substrates, the aluminum response was used to subtract the contribution of the substrate from the overall response of the specimen. The resulting shear stressstrain curves for the coating revealed a shear modulus of $50 \mathrm{GPa}$ and a shear strength of about $50 \mathrm{MPa}$. No significant difference could be observed between microstructured and nanostructured coatings except for peak shear stress and softening rate. 

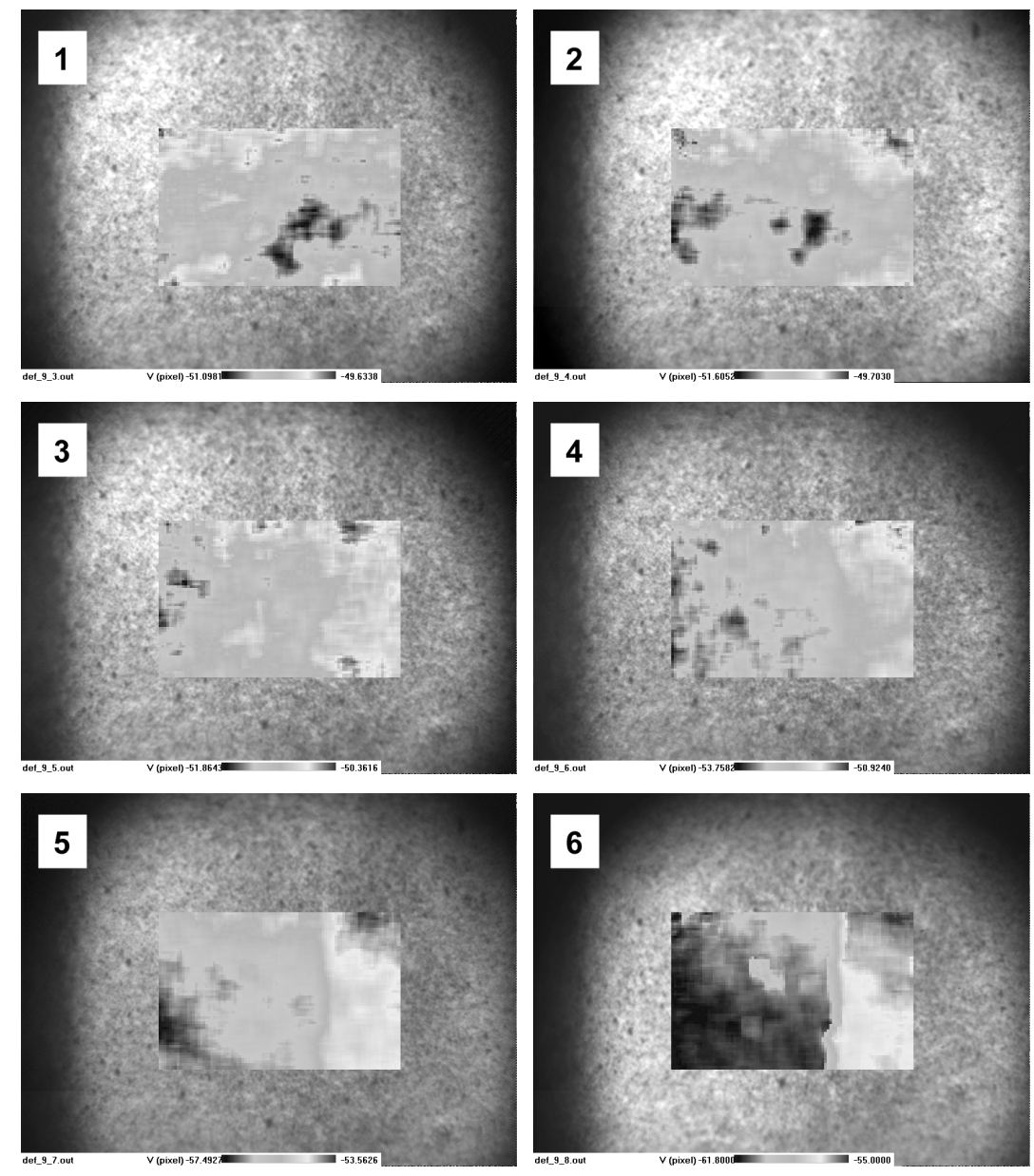

Fig. 12-High-speed photography images and vertical displacements fields from a dynamic shear test performed on nanocrystalline WC-Co coated Al7075-T6 specimen. A mode III crack appears in frame 4.
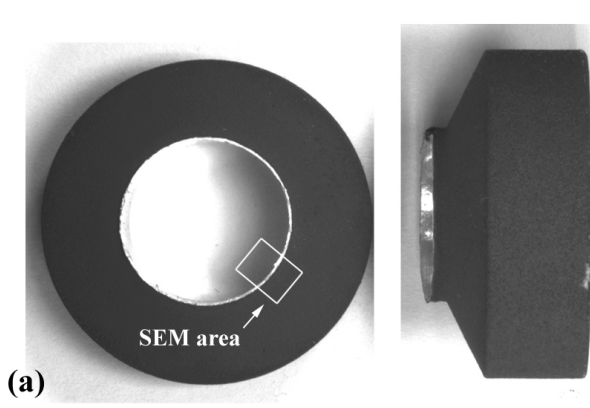

(b)
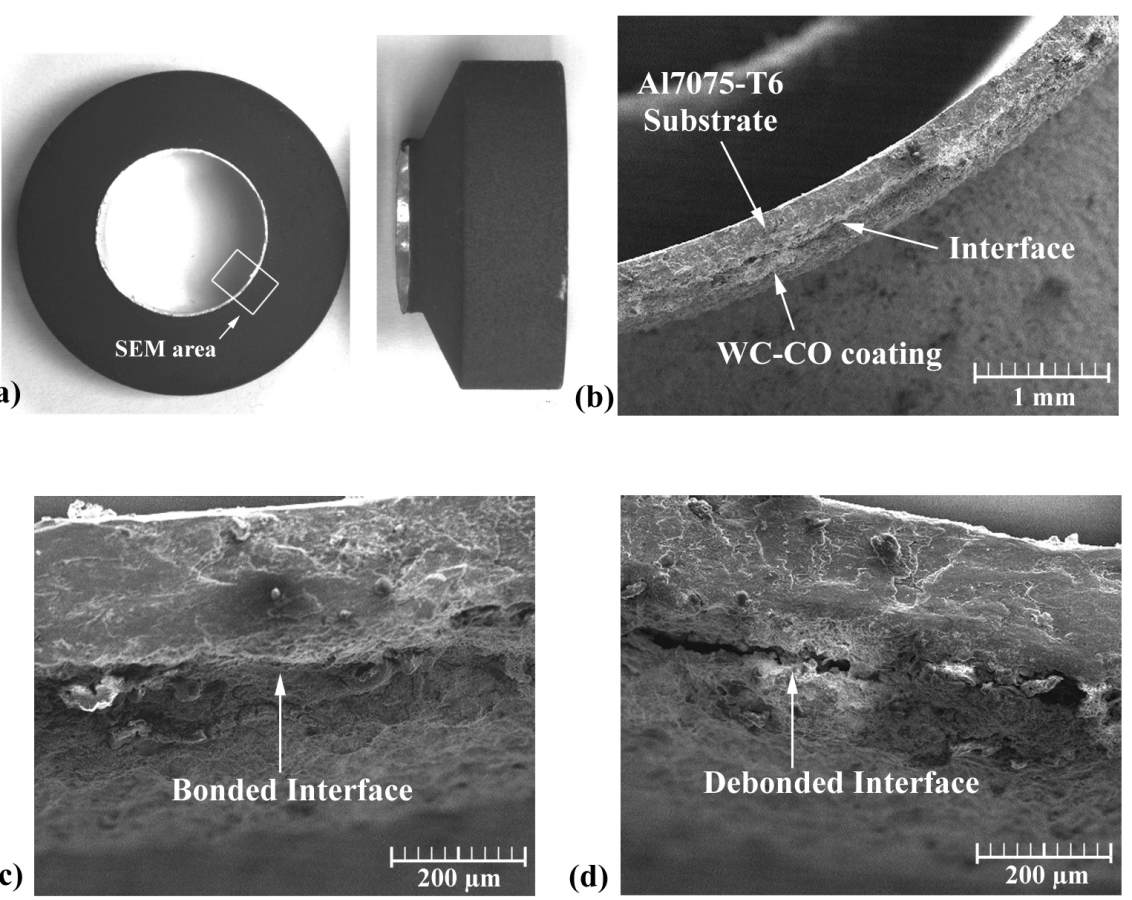

(d)

Fig. 13-SEM images acquired from a recovered nanocrystalline WC-Co coated AI7075-T6 specimen: (a) photograph of split specimen; (b) SEM image of WC-Co/Al interface as revealed by the fracture surface; (c) and (d) higher magnification SEM images showing regions of bonded and debonded WC-Co/Al interface. 
The properties identified in this paper are below reference values for WC-Co bulk materials. This must be attributed to porosity in the coatings, as well as internal damage created by residual stresses during the coating process.

In some instances, the coating exhibited cracks in both circumferential and radial directions. ${ }^{31}$ The circumferential cracks, running parallel to the coating-aluminum interface, are expected to be much less detrimental to the coating torsional strength than the radial cracks.

High-speed photography used with DIC was used to detect early cracking in the specimen and to elucidate the modes of deformations at different stages of the stressstrain curves. The results emphasized the importance of the coating-substrate interactions.

Although the properties of the WC-Co nanocoating were far from optimum, a methodology for investigating damage kinetics and failure has been established. This methodology can be applied to examine the behavior of other advanced materials that can be manufactured as coatings on ductile substrates. Manufacturing coatings free of initial microcracks remains a significant challenge. Research on optimization of the spray deposition parameters should be pursued to produce high-quality nanostructured coatings that can fully exploit the benefits of nanosized grains.

\section{Acknowledgments}

The authors would like to express a special thank to Dr. Larry Kabacoff for providing continuous encouragement through this research effort. Likewise, the support from Dr. Robert Ringel, president of A\&A Co., in the manufacturing of the coated specimens is highly appreciated. The Office of Naval Research, through Young Investigator Award No N00014-97-1-0550, supported this research.

\section{References}

1. Hall, E.O., "The Deformation and Ageing of Mild Steel. 2. Characteristics of the Luders Deformation," Proc. Phys. Soc. B, 64, 747-753 (1951).

2. Petch, N.J., "The Cleavage Strength of Polycrystals," J. Iron Steel Inst., 174, 25-28 (1953).

3. Zhang, Z., Wahlberg, S., Wang, M., and Muhammad, M., "Processing of Nanostructured WC-Co Powder from Precursor Obtained by Coprecipitation," Nanostructured Materials, 12, 163-166 (1999).

4. Kung, H. and Foecke, T., "Mechanical Behavior of Nanostructured Materials," MRS Bulletin, 24, 14-15 (1999).

5. Weertman, J.R., Farkas, D., Hemker, K., Kung, H., Mayo, M., Mitra, $R$., and van Swygenhoven, H., "Structure and Mechanical Behavior of Bulk Nanocrystalline Materials," MRS Bulletin, 24, 44-50 (1999).

6. Nieh, T.G. and Wadsworth, J., "Hall-Petch Relation in Nanocrystalline Solids," Scripta Metall. Mater, 25, 955-958 (1991).

7. Scattergood, R.O. and Koch, C.C., "A Modified-Model for Hall-Petch Behavior in Nanocrystalline Materials," Scripta Metall. Mater., 27, 1195 1200 (1992).

8. Coble, R.L., "A Model for Boundary Diffusion Controlled Creep in Polycrystalline Materials," Journal of Applied Physics, 34, 1679-1688 (1963).

9. Mayo, M.J., Siegel, R.W., Narayamy, A., and Nix, W.D., "Mechanical
Properties of Nanophase $\mathrm{TiO}_{2}$ as Determined by Nanoindentation," Journal of Materials Research, 5, 1073-1082 (1990).

10. Mayo, M.J., Siegel, R.W., Liao, Y.X., and Nix, W.D., "Nanoindentation of Nanocrystalline ZNO," Journal of Materials Research, 7, 973-979 (1992).

11. Nieh, T.G., McNally, C.M., and Wadsworth, J., "Superplastic Behavior of a 20-Percent $\mathrm{Al}_{2} \mathrm{O}_{3} /$ YTZ Ceramic Composite," Scripta Metall. Mater., 23, 457-460 (1989).

12. Nieh, T.G., Wadsworth, J., and Wakai, F., "Recent Advances in Superplastic Ceramics and Ceramic Composites," Int. Mater. Rev., 36, 146-161 (1991).

13. Maehara, Y. and Langdon, T.G., "Superplasticity in Ceramics," Journal of Materials Science, 25, 2275-2286 (1990).

14. Mayo, M.J., "High and Low Temperature Superplasticity in Nanocrystalline Materials,” Nanostructured Materials, 9, 717-726 (1997).

15. Espinosa, H.D. and Nemat-Nasser, S., ASM Handbook, Mechanical Testing and Evaluation, Vol. 8 (2000).

16. Ruiz, C. and Mines, R.A.W., "The Hopkins Pressure Bar-An Alternative to the Instrumented Pendulum for Charpy Tests," Int. J. Fracture, 29, 101-109(1985).

17. Kobayashi, T., Yamamoto, I., and Niinomi, M., "Evaluation of Dynamic Fracture-toughness Parameters by Instrumented Charpy Impact Test," Engineering Fracture Mechanics, 24, 773-782 (1986).

18. Eftis, J. and Krafft, J.M., "A Comparison of Initiation with Rapid Propagation of a Crack in a Mild Steel Plate," J. Basic Eng., Trans. ASME, 87, 257-266 (1965).

19. Prakash, V., Freund, L.B., and Clifton, R., "Stress Wave Radiation from a Crack Tip During Dynamic Initiation,” Trans. ASME, 165, 356-365 (1992).

20. Subbash, G. and Ravichandran, G., ASM Handbook, Mechanical Testing and Evaluation, Vol. 8 (2000).

21. Nemat-Nasser, S., ASM Handbook, Mechanical Testing and Evaluation, Vol. 8 (2000).

22. Espinosa, H.D., Patanella, A., and Xu, Y., "Dynamic Compressionshear Response of Brittle Materials with Specimen Recovery," EXPERIMENTAL MECHANICS, 40, 321-330 (2000).

23. Espinosa, H.D., Zavattieri, P.D., and Dwivedi, S., "A Finite Deformation Continuum Discrete Model for the Description of Fragmentation and Damage in Brittle Materials," Special Issue of Journal of the Mechanics and Physics of Solids, 46, 1909-1942 (1998).

24. Zavattieri, P.D., Raghuram, P., and Espinosa, H.D., "A Computational Model of Ceramic Microstructures Subjected to Multi-axial Dynamic Loading," Journal of the Mechanics and Physics of Solids, 49, 27-68 (2000).

25. Kolsky, H., "The Propagation of Longitudal Elastic Waves Along Cylindrical Bars," Phil. Mag., 45, 712-730 (1954).

26. Espinosa, H.D., Patanella, A., and Fischer, M., "Dynamic Friction Measurements at Sliding Velocities Representative of High-speed Machining Processes,” Journal of Tribology, 122, 834-848 (2000).

27. Espinosa, H.D., Patanella, A., and Fischer, M., "A Novel Dynamic Friction Experiment Using a Modified Kolsky Bar Apparatus," EXPERIMENTAL MECHANICS, 40, 138-153 (2000).

28. Chu, T.C., Ranson, W.F., Sutton, M.A., and Peters, W.H., "Application of Digital-image-correlation Techniques to Experimental Mechanics," EXPERIMENTAL MECHANICS, 25, 232-244 (1985).

29. Bruck, H.A., McNeill, S.R., Sutton, M.A., and Peters, W.H., "Digital Image Correlation Using Newton-Raphson Method of Partial Differential Correction," EXPERIMENTAL MECHANICS, 29, 261-267 (1989).

30. Barthelat, F., Malukhin, K., and Espinosa, H.D., "Quasi-static and Dynamic Torsion Testing of Ceramic Micro- and Nano-structured Coating Using Speckle Photography," Recent Advances in Experimental Mechanics, a special volume in honor of Professor I.M. Daniel, 14th US National Congress of Theoretical and Applied Mechanics, 23-28 June, Blacksburg, VA, Kluwer, Dordrecht (2002).

31. Espinosa, H.D., ONR Report, Award No N00014-97-1-0550 (2001). 